\title{
Characteristics of KIT-negative gastrointestinal stromal tumours and diagnostic utility of protein kinase $\mathbf{C}$ theta immunostaining
}

H E Lee, M A Kim, H S Lee, B L Lee and W H Kim

J. Clin. Pathol. 2008;61;722-729; originally published online 1 Apr 2008;

doi:10.1136/jcp.2007.052225

Updated information and services can be found at:

http://jcp.bmj.com/cgi/content/full/61/6/722

These include:

References This article cites 29 articles, 13 of which can be accessed free at:

http://jcp.bmj.com/cgi/content/full/61/6/722\#BIBL

Rapid responses You can respond to this article at:

http://jcp.bmj.com/cgi/eletter-submit/61/6/722

Email alerting Receive free email alerts when new articles cite this article - sign up in the box at service the top right corner of the article

Topic collections Articles on similar topics can be found in the following collections

Molecular genetics (1488 articles)

Immunology (including allergy) (13934 articles)

Notes

To order reprints of this article go to:

http://journals.bmj.com/cgi/reprintform

To subscribe to Journal of Clinical Pathology go to:

http://journals.bmj.com/subscriptions/ 


\title{
Characteristics of KIT-negative gastrointestinal stromal tumours and diagnostic utility of protein kinase $\mathrm{C}$ theta immunostaining
}

\author{
H E Lee, ${ }^{1}$ M A Kim, ${ }^{1}$ H S Lee, ${ }^{3}$ B L Lee, ${ }^{2}$ W H Kim',
}

${ }^{1}$ Department of Pathology, Seoul National University College of Medicine, Seoul, Korea; ${ }^{2}$ Cancer Research Institute, Seoul National University College of Medicine, Seoul, Korea; ${ }^{3}$ Department of Pathology, Seoul National University Bundang Hospital, Seongnam, Korea

Correspondence to: Dr W H Kim, 28 Yeongeon-dong, Seoul 110-799, Korea; woohokim@snu.ac.kr

Accepted 29 February 2008 Published Online First 1 April 2008

\begin{abstract}
Aims: To characterise KIT-negative gastrointestinal stromal tumours (GISTs) clinically, pathologically, immunohistochemically and genetically, and to establish the usefulness of protein kinase $\mathrm{C}$ theta (PKC $\theta$ ) as a diagnostic marker in KIT-negative GIST.
\end{abstract}

Methods: 252 consecutive cases of GIST were evaluated for clinicopathological characteristics and immunostained for various antibodies. Mutational analyses of KIT and platelet-derived growth factor receptor $\alpha$ (PDGFRA) were also performed in 62 cases.

Results: 20 (7.9\%) GISTs showed negative immunostaining for KIT. KIT-negative GISTs were more likely to originate from omentum or peritoneum, have an epithelioid histology, and be classified as high risk. The overall survival rate of patients with KIT-negative GISTs (5-year survival rate 68.7\% (SD 10.7\%)) was lower than that of patients with KIT-positive GISTs (5-year survival rate, $79.9 \%(3.0 \%))(p=0.042$, log-rank test). Negative $\mathrm{KIT}$ expression was an independent prognostic factor in multivariate Cox regression analysis when the risk of aggressive behaviour and the status of imatinib treatment were adopted as covariates. KIT-negative GISTs also showed lower expression rates of CD34, Bcl-2, and PKC $\theta$ than KIT-positive GISTs; mutational analysis revealed that 30\% of KIT-negative GISTs harboured a PDGFRA exon 18 mutation. Immunostaining on PKC $\theta$ showed that $93.9 \%$ of all GISTs expressed PKC $\theta$ protein. However, $21.9 \%$ of 64 mesenchymal tumours other than GIST also showed positivity on PKC $\theta$.

Conclusions: KIT-negative GISTs had characteristics that differ from those of KIT-positive GISTs, and negative KIT expression was an independent prognostic indicator for overall survival of patients. Although PKCO is a sensitive diagnostic marker for GIST, its usefulness is limited because of low sensitivity and low specificity in KITnegative GISTs.

Gastrointestinal stromal tumour (GIST) is the most common mesenchymal tumour of the gastrointestinal tract, and is thought to originate from interstitial cells of Cajal. ${ }^{1}$ GIST is characterised by the expression of the type III receptor tyrosine kinase KIT encoded by the KIT proto-oncogene, ${ }^{2}$ thus KIT immunohistochemistry (IHC) has been used as a diagnostic marker of GIST. ${ }^{2}{ }^{3}$ Since Hirota et al first reported the KIT mutation in $1998,{ }^{4}$ many reports have demonstrated that the majority of GISTs harbour oncogenic mutations of KIT. ${ }^{5}{ }^{6}$ It was also discovered that a small subset of GISTs $(5-7 \%)$ has activating mutations of platelet-derived growth factor receptor $\alpha$ (PDGFRA)..$^{78}$ Recently, therapeutic targeting of mutant KIT with the tyrosine kinase inhibitor, imatinib mesylate has proven to be effective in patients with advanced or unresectable GISTs. ${ }^{10}$

Previous studies have also indicated that $5-10 \%$ of GISTs express little or no KIT. ${ }^{11}{ }^{12}$ These KITnegative GISTs are believed to be somewhat different from KIT-positive GISTs clinically, pathologically and genetically. Medeiros et al reported that KIT-negative GISTs were more likely to have epithelioid cell morphology, arise in the omentum/peritoneal surface, and harbour oncogenic mutations of PDGFRA.$^{13}$ Other papers about KIT-negative GISTs have described similar features. ${ }^{14} 15$ However, there have been few direct comparisons of KIT-negative GISTs with KITpositive GISTs clinically, pathologically, immunohistochemically and genetically, and few data on disease-free survival (DFS) and overall survival (OS) rate of patients with KIT-negative GISTs.

The observation that a subset of KIT-negative GISTs is also responsive to imatinib emphasised the importance of correct diagnosis in KIT-negative cases. $^{16}$ Although GIST diagnosis is based on clinical and histopathological features, it needs experience and can be subjective. Recently, IHC of DOG1 and protein kinase C theta (PKC $\theta$ ) was suggested as a diagnostic marker of GISTs, especially in KIT-negative cases. ${ }^{15}{ }^{17-20}$ Gene expression studies using DNA microarrays have also revealed that the gene encoding PKC $\theta$ is overexpressed in GISTs. ${ }^{21}{ }^{22}$ In addition, some previous reports showed that PKC $\theta$ is highly expressed in GIST tissues by IHC and suggested that PKC $\theta$ immunostaining can be used as a diagnostic marker of GIST. ${ }^{15}{ }^{18-20}$ However, more data on sensitivity and specificity of PKC $\theta$ for GIST diagnosis are required before PKC $\theta$ can be used as a diagnostic marker of GIST in routine clinical study.

Here, we compare the clinicopathological, immunohistochemical and genetic characteristics of KIT-positive and KIT-negative GISTs and evaluate the usefulness of PKC $\theta$ as a diagnostic marker.

\section{METHODS}

\section{Tissue samples}

A total of 252 surgically resected consecutive GIST cases examined at the Department of Pathology, Seoul National University Hospital over a period of 16 years (1989 to 2005) were collected. These tumours were clinically and histologically classified as GISTs based on previous experience of the clinical and histological spectrum of GIST. In detail, the tumours showed intersecting fascicles, 
Table 1 Antibodies used for the immunohistochemical study

\begin{tabular}{llll}
\hline Antibody & Retrieval methods & Dilution & Source \\
\hline KIT & Microwave & $1: 250$ & Dako $\dagger$ \\
CD34 & Microwave & $1: 100$ & Immunotech $\$$ \\
SMA & Microwave & $1: 150$ & Dako $\dagger$ \\
S-100 & None & $1: 150$ & Dako $\dagger$ \\
Desmin & Autoclave & $1: 150$ & Dako $\dagger$ \\
Bcl-2 & Microwave & $1: 100$ & Dako $\dagger$ \\
PKC $\theta$ & Autoclave in Borg & $1: 15$ & BD Biosciences§ \\
& Decloaking Chamber & & \\
& (Biocare Medical) & & \\
\hline
\end{tabular}

*Biocare Medical, Walnut Creek, California, USA; †Dako, Glostrup, Denmark; \#Immunotech, Marseille, France; §BD Biosciences, Franklin Lakes, New Jersey, USA.

nuclear palisading, organoid pattern, or rarely, less cohesive pattern, being composed of spindle or epithelioid cells with eosinophilic cytoplasm and ill-defined cytoplasmic border. Most of the tumours had uniform appearance with evenly distributed chromatin, but rare tumours showed pleomorphic and anaplastic features. The diagnosis of GIST was confirmed by KIT positivity on IHC. For KIT-negative cases, the diagnosis of GIST was limited to the tumours with negative staining on smooth muscle actin (SMA) and desmin on IHC.

Age and sex of patients and tumour site and size were evaluated by reviewing pathological records and/or medical charts. Glass slides were reviewed to determine histological features. The risk of aggressive behaviour was assessed using the criteria of the National Institute of Health GIST workshop. ${ }^{3}$ Disease stage at presentation (local, loco-regional and metastatic disease) and resection margin status (R0, complete resection; R1, microscopic incomplete resection; R2, macroscopic incomplete resection) of each case were also obtained. Whereas none of the patients had received preoperative chemotherapy or radiotherapy, 33/249 patients (13.3\%) were treated with imatinib due to residual, metastatic or recurrent disease after surgery. Follow-up of patients has been performed
Table 2 Primer sequences used in this study

\begin{tabular}{lll}
\hline & Forward & Reverse \\
\hline KIT exon 9 & ATGCCACATCCCAAGTGTTT & TGACATGGTCAATGTTGGAA \\
KIT exon 11 & CGTAATCGTAGCTGGCATGA & AAACAAAGGAAGCCACTGGA \\
PDGFRA exon 12 & TCCAGTCACTGTGCTGCTTC & TCTGCCAAGGCCTATAAATTG \\
PDGFRA exon 18 & ACCATGGATCAGCCAGTCTT & GCACCGAATCTCTAGAAGCAA \\
\hline
\end{tabular}

with imaging modalities including abdomen CT and/or ultrasonography in all cases; the interval of follow-up was usually 6 month. Disease status was categorised as dead of disease, dead of other cause, alive without disease, alive with disease, or lost during follow-up. The duration of DFS was the time between surgery and first recurrence/metastasis or last follow-up. Recurrence and metastasis were defined when any subsequent occurrence of tumour in and outside the original location of tumour was suspicious on imaging, respectively. The duration of OS was the interval between surgery and death or last follow-up. Deaths from unrelated causes were censored.

Fifty-three cases of surgically resected non-GIST mesenchymal tumours in the gastrointestinal tract (non-GIST) (35 leiomyomas, 7 leimyosarcomas, 7 schwannomas, 2 desmoid tumours, 1 inflammatory fibroid polyp, and 1 undifferentiated sarcoma) were collected from Seoul National University Hospital and examined for PKC $\theta$ expression status using the tissue microarray method. In addition, 11 desmoid tumours from Seoul National University Bundang Hospital were examined and immunostained with PKC $\theta$ antibody using full section slides.

\section{Tissue microarray method and immunohistochemistry}

Core tissue biopsies (2 $\mathrm{mm}$ in diameter) were taken from individual paraffin-embedded tumour tissues and arranged in new recipient paraffin blocks (tissue array block) using a trephine apparatus (Superbiochips Laboratories, Seoul, Korea). Each tissue array block contained up to 60 cases, and the eight
Figure 1 KIT-negative gastrointestinal stromal tumours. $(A, B)$ The case with platelet-derived growth factor receptor $\alpha$ (PDGFRA) mutation (D842V). (A) The tumour shows vague organoid pattern and is composed of epithelioid cells with myxoid stroma. (B) The tumour represents total negativity on KIT immunostaining. Interspersed mast cells are positive for KIT. $(C, D)$ The case with no KIT or PDGFRA mutation. (C) The tumour shows epithelioid cell histology. (D) KIT immunohistochemistry is totally negative. Original magnification, $\times 200$.
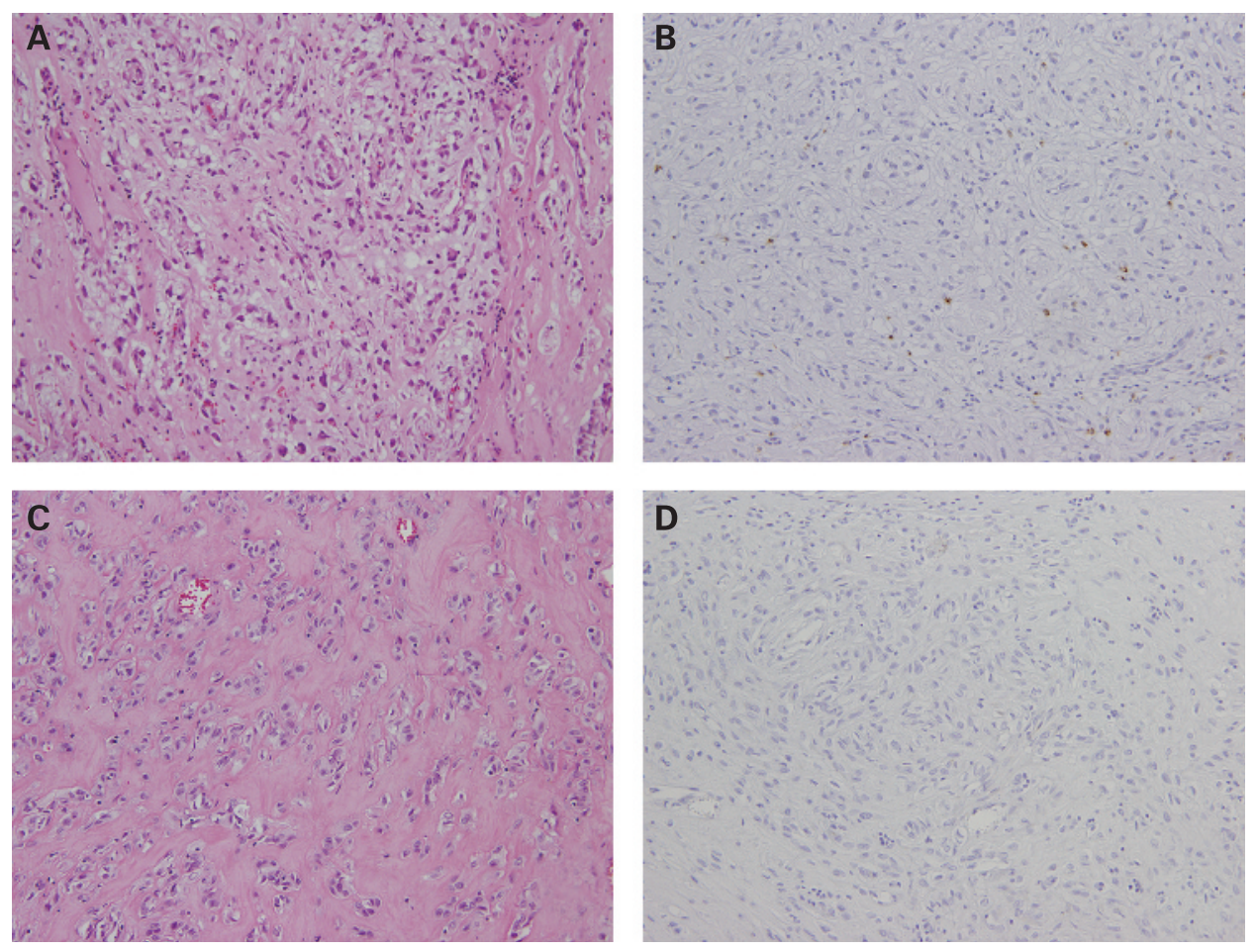
array blocks prepared containing a total of 252 GIST and 53 non-GIST tissues. Sections $(4 \mu \mathrm{m})$ were cut from each tissue array block, dewaxed, and dehydrated.

Immunohistochemical staining for various proteins was performed on microarray slides using a streptavidin peroxidase procedure. Table 1 present the primary antibodies used in this study. For KIT, tissue sections were microwaved in sodium citrate buffer, pH 6.0 for 15 min for epitope retrieval. For PKC $\theta$, antigen retrieval was performed by autoclaving the tissue sections in Borg Decloaking Chamber (Biocare Medical, Walnut Creek, California, USA) at $120^{\circ} \mathrm{C}$ for $3 \mathrm{~min}$. The sections were incubated with the antibodies to KIT (1:250, rabbit polyclonal; Dako, Glostrup, Denmark) or PKC $\theta$ (1:15, mouse monoclonal, clone 27; BD Biosciences, Franklin Lakes, New Jersey, USA). Antibody binding was detected using an avidin-biotin-peroxidase complex (Vectastatin Elite ABC Kit PK-6100; Vector Laboratories, Burlingame, California, USA) for $30 \mathrm{~min}$. The peroxidase reaction was visualised by incubating with 3,3'-diaminobenzidine tetrahydrochloride (DAB Kit SK4100; Vector Laboratories) for 3 min. Interspersed mast cells and interstitial cells of Cajal were used as a positive control for KIT. For positive control of PKC $\theta$, nerve plexus was used. Smooth muscle was a negative control for both KIT and PKC $\theta$ staining. Staining results were scored as positive (immunoreactivity in $\geqslant 10 \%$ of tumour cells) or negative (immunoreactivity in $<10 \%$ of tumour cells).

Specifically, 30 cases showing complete negativity or very weak positivity for KIT immunostaining in microarray slides were subject to repeat IHC using full section slides considering possible heterogeneity of tumour in GIST. Finally, KIT-negative GIST was referred when the tumour showed immunoreactivity in $<10 \%$ of tumour cells in their full section slide. As a result, 20 cases were categorised as KIT-negative GIST. We also confirmed PKC $\theta$ IHC results using full section slides for all 20 KIT-negative GISTs.

\section{DNA extraction and direct sequencing}

Genomic DNA of formalin or methanol fixed paraffin embedded tissues, including 62 cases of randomly selected KIT-positive GISTs and all 20 cases of KIT-negative GISTs, was extracted using the standard proteinase-K digestion/phenol-chloroform procedure. PCR was performed using $1 \mu \mathrm{l}$ DNA solution, $0.1 \mu \mathrm{l}$ TaKaRa Taq (TaKaRa Bio, Shiga, Japan), $1 \mu \mathrm{l}$ dNTP (2 mM each), $1 \mu \mathrm{l}$ buffer, $0.5 \mu \mathrm{l}$ each primer $(5 \mathrm{pmol} / \mu \mathrm{l})$ in a final volume of $10 \mu \mathrm{l}$. Table 2 presents the primer sequences used in this study. Thirty-five amplification cycles of denaturation at $95^{\circ} \mathrm{C}$ for $30 \mathrm{~s}$, annealing at $58^{\circ} \mathrm{C}$ for $30 \mathrm{~s}$, and extension at $72^{\circ} \mathrm{C}$ for $1 \mathrm{~min}$ were performed in GeneAmp PCR System 9700 (Applied Biosystems, Foster City, California, USA). PCR products were treated with ExoSAP-IT (USB, Cleveland, Ohio, USA) and sequenced using BigDye Terminator v3.1 Ready Reaction Cycle Sequencing Kits (Applied Biosystems). Sequenced products were analysed on an ABI Prism 3100 genetic Analyser (Applied Biosystems).

\section{Statistical analyses}

The $\chi^{2}$ test or Fisher's exact test was used to determine correlations between KIT expressional status and clinicopathological parameters, IHC results or mutational status. Student t test was used to compare means of patient's age, tumour size, and mitotic count of tumours between KIT-positive and KIT-negative GISTs. Survival curves were estimated using the Kaplan-Meier product-limit method; the significance of difference between survival curves was determined using the log-rank test. Multivariate survival analysis using the Cox proportional hazards model was performed adopting the status of KIT expression, the risk of aggressive behaviour, and the status of imatinib treatment as covariates. Results were considered statistically significant for $p$ values less than 0.05 . All statistical analyses were conducted using SPSS V.15.0.

\section{RESULTS}

\section{Clinicopathological characteristics of KIT-positive and KIT- negative GISTs}

The 252 GIST cases were divided into KIT-positive ( $n=232$; $92.1 \%$ ) and KIT-negative GISTs ( $n=20 ; 7.9 \%$ ) according to IHC results. Table 3 summarises clinicopathological characteristics. Median age of patients of KIT-positive and KIT-negative GIST was 58 years (range 23-85) and 56 years (range 26-82), respectively; median size of tumours in KIT-positive and KITnegative cases was $6.0 \mathrm{~cm}$ (range $0.3-23.0$ ) and $6.0 \mathrm{~cm}$ (range 0.5-30.0), respectively. Compared with KIT-positive GISTs, KIT-negative GISTs more often originated from colon, omentum or mesentery. Fifty-five per cent of KIT-negative GISTs had

Table 3 Clinicopathological characteristics of KIT-positive and KITnegative gastrointestinal stromal tumours

\begin{tabular}{|c|c|c|c|}
\hline & $\begin{array}{l}\text { KIT-positive } \\
\text { cases } \\
n(\%)\end{array}$ & $\begin{array}{l}\text { KIT-negative } \\
\text { cases } \\
\text { n ( } \%)\end{array}$ & p Value \\
\hline Mean age (SD) (years) & $57.10(11.36)$ & $56.80(12.78)$ & $0.909 \dagger$ \\
\hline Sex & & & $0.302 \div$ \\
\hline Male & $123(53.0)$ & $13(65.0)$ & \\
\hline Female & $109(47.0)$ & $7(35.0)$ & \\
\hline Primary site & & & $0.042^{*}$ \\
\hline Stomach & $133(57.3)$ & $10(50.0)$ & \\
\hline Small bowel & $69(29.7)$ & $3(15.0)$ & \\
\hline Large bowel & $14(6.0)$ & $4(20.0) \S$ & \\
\hline Omentum or mesentery & $16(6.9)$ & $3(15.0)$ & \\
\hline Mean of tumour size (SD) $(\mathrm{cm})$ & $7.13(5.20)$ & $10.30(10.02)$ & $0.177 \dagger$ \\
\hline $\begin{array}{l}\text { Mean of mitotic counts } / 50 \\
\text { HPF (SD) }\end{array}$ & $14.35(26.22)$ & $45.20(76.40)$ & $0.088 \dagger$ \\
\hline Histological type & & & $<0.001+$ \\
\hline Spindle & $198(86.5)$ & $9(45.0)$ & \\
\hline Epithelioid & $31(13.5)$ & $11(55.0)$ & \\
\hline Risk of aggressive behaviour & & & $0.316^{*}$ \\
\hline Very low risk & $21(9.1)$ & $3(15.0)$ & \\
\hline Low risk & $55(23.7)$ & $3(15.0)$ & \\
\hline Intermediate risk & $52(22.4)$ & $2(10.0)$ & \\
\hline High risk & $104(44.8)$ & $12(60.0)$ & \\
\hline Stage at presentation & & & $0.006^{*}$ \\
\hline Local disease & $203(88.6)$ & $13(65.5)$ & \\
\hline Loco-regional disease & $2(0.9)$ & $0(0)$ & \\
\hline Metastatic disease & $24(10.5)$ & $7(35.5)$ & \\
\hline Resection margin status & & & $0.791^{*}$ \\
\hline Ro & $193(84.3)$ & $17(85)$ & \\
\hline $\mathrm{R} 1$ & $5(2.2)$ & $0(0)$ & \\
\hline $\mathrm{R} 2$ & $31(13.5)$ & $3(15)$ & \\
\hline Last follow-up status & & & $0.064^{*}$ \\
\hline Dead of disease & $43(18.5)$ & $6(30)$ & \\
\hline Dead of other cause & $12(5.2)$ & $3(15)$ & \\
\hline Alive without disease & $92(39.7)$ & $6(30)$ & \\
\hline Alive with disease & $11(4.7)$ & $1(5)$ & \\
\hline Lost & $74(31.9)$ & $4(20)$ & \\
\hline
\end{tabular}

*Fisher's exact test; $\uparrow$ Student $t$ test; $\$ \chi^{2}$ test.

$\S$ All four tumours were located in the colon.

HPF, high power fields; R0, complete resection; R1, microscopic incomplete resection; $\mathrm{R} 2$, macroscopic incomplete resection. 
Figure 2 Kaplan-Meier plots for survival of the 252 patients with gastrointestinal stromal tumours (GISTs) as a function of the risk of aggressive behaviour $(A, B)$ and as a function of the $\mathrm{KIT}$ expression status $(C, D)$. As the risk is higher, disease-free $(A)$ and overall $(B)$ survival rates become lower $(p<0.001$ for both comparisons, log-rank tests). The cases of KIT-negative GIST had poorer disease-free (C) and overall (D) survival than those of KIT-positive GIST ( $p=0.153$ and $p=0.042$, respectively, log-rank tests).
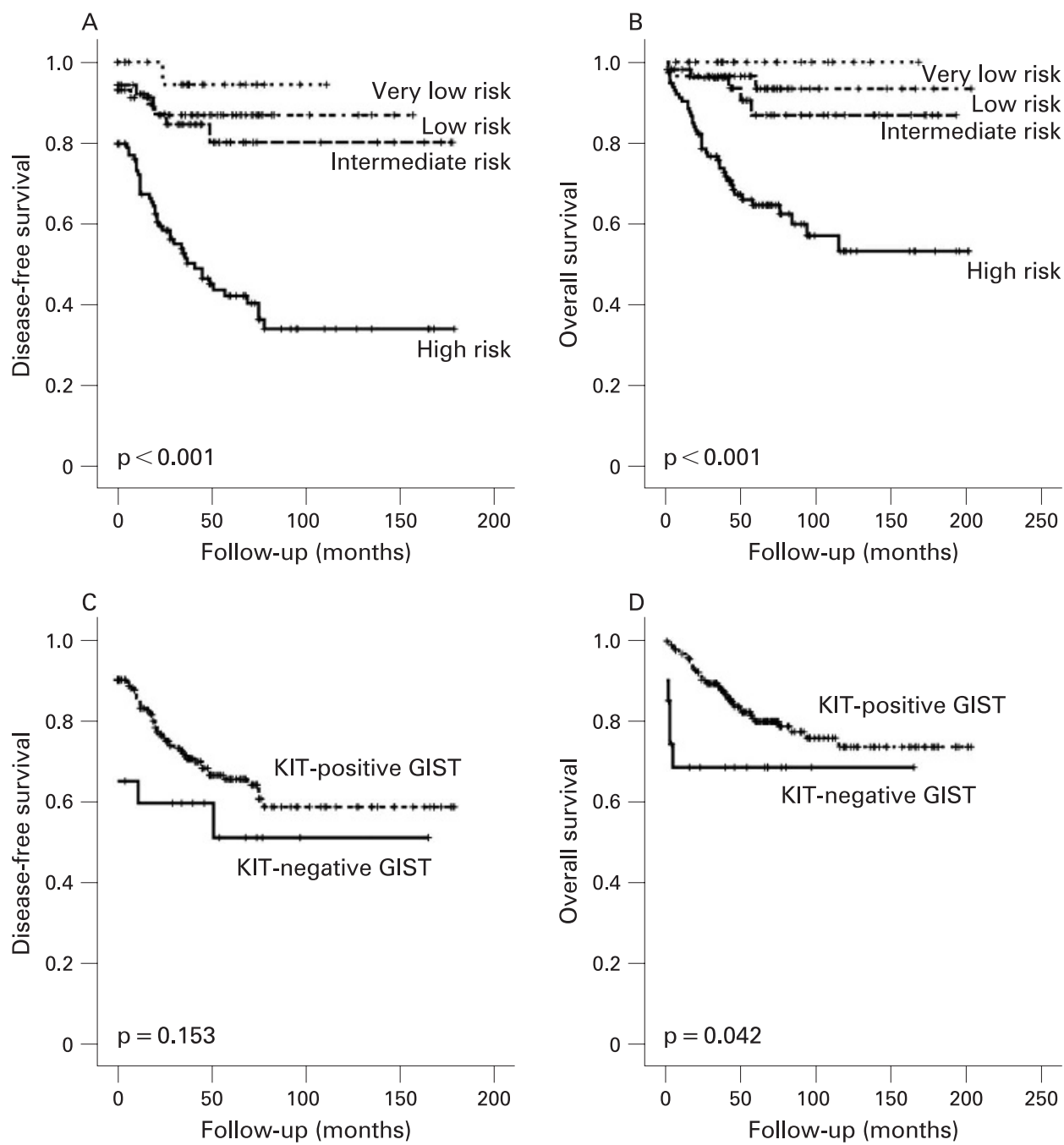

an epithelioid histology (fig 1); this was significantly higher than that of KIT-positive GISTs $(p<0.001)$. In terms of the risk of aggressive behaviour, KIT-negative GISTs more frequently belonged to the high-risk group than KIT-positive GISTs, but the difference was not significant. Also, KIT-negative GISTs more frequently manifested with metastatic disease at presentation and had a higher risk of dying of disease than KITpositive GISTs. Because the cases were collected mainly from the pre-imatinib era, only 33 cases were treated with imatinib; 2 of these had KIT-negative GIST.

Table 4 Multivariate Cox proportional hazards model for the predictors of overall survival

\begin{tabular}{llr}
\hline Variables & $\begin{array}{l}\text { Hazard ratio } \\
(\mathbf{9 5 \%} \mathbf{C l})\end{array}$ & p Value \\
\hline $\begin{array}{l}\text { KIT expression } \\
\text { KIT-negative }\end{array}$ & 0.030 \\
$\quad$ KIT-positive & $2.596(1.097$ to 6.147$)$ & \\
$\begin{array}{l}\text { Risk of aggressive behaviour } \\
\text { Low and very low risk }\end{array}$ & 0.000 & $<0.001$ \\
$\quad$ Intermediate risk & $0.199(0.078$ to 0.508$)$ & \\
$\quad$ High risk & 1.000 & \\
Imatinib treatment & $3.531(1.254$ to 9.942$)$ & \\
$\quad$ No & 1.000 & \\
Yes & & \\
\hline
\end{tabular}

\section{Survival analyses}

As expected, there was a significant correlation between risk of aggressive behaviour and the clinical outcome of patients. Kaplan-Meier curves for DFS and OS reflected the prognostic value of the histologically determined risk $(p<0.001$ for both comparisons, log-rank tests; fig 2A,B), also demonstrating the accuracy of sampling of our patient group.

In the OS analysis of 78 patients with recurrent or metastatic disease, patients receiving imatinib treatment had a better survival rate than those not receiving it (median survival time, 24 vs 52 months; $p<0.001$, log-rank test). Patients who had KIT-negative GIST had a worse prognosis than those having KIT-positive GIST ( $p=0.153$ for DFS and $p=0.042$ for OS, logrank for both comparisons; fig 2C,D). Patients with KITnegative GISTs had a median duration of DFS of 31.5 (range 0

Table 5 Immunohistochemical results for KIT-positive and KIT-negative gastrointestinal stromal tumours

\begin{tabular}{lllr}
\hline & KIT-positive & KIT-negative & p Value* \\
\hline CD34 & $195(84.1)$ & $7(35.0)$ & $<0.001$ \\
S-100 protein & $24(10.3)$ & $1(5.0)$ & 0.443 \\
Bcl-2 & $188(95.9)$ & $8(40.0)$ & $<0.001$ \\
PKC $\theta$ & $216(93.5)$ & $15(75.0)$ & $<0.001$ \\
\hline
\end{tabular}

The number and percentage (in parentheses) of positive cases are reported for each marker.

${ }^{*} \chi^{2}$ test. 
Table 6 Mutational status of KIT-positive and KIT-negative gastrointestinal stromal tumours

\begin{tabular}{lll}
\hline & $\begin{array}{l}\text { KIT-positive } \\
(\%)\end{array}$ & $\begin{array}{l}\text { KIT-negative } \\
(\%)\end{array}$ \\
\hline KIT exon 9 & $3(4.8)$ & $0(0)$ \\
KIT exon 11 & $31(50.0)$ & $0(0)$ \\
PDGFRA exon 12 & Not performed & $0(0)$ \\
PDGFRA exon 18 & Not performed & $6(30.0)$ \\
\hline
\end{tabular}

165) months and a median duration of OS of 23 (range 1-165) months, as compared with 34 (range 0-179) and 53.5 (range 1203) months, respectively, in patients with KIT-positive GIST. The 5-year OS rate was $68.7 \%$ (SD 10.7\%) in patients with KITnegative GIST, but $79.9 \%$ (SD 3.0\%) in patients with KITpositive GIST. The DFS rate at 5 years was $51.1 \%$ (SD 12.3\%) in patients with KIT-negative GIST and 65.5\% (SD 3.7\%) in patients with KIT-positive GIST. Thus, negative KIT expression seems to be useful for defining a subgroup with unfavourable prognosis in GISTs. Also, multivariate Cox regression analysis for the prediction of OS revealed that negative KIT expression was an independent prognostic factor when the risk of aggressive behaviour and the status of imatinib treatment were adopted as covariates in the analysis (hazard ratio 2.596 (95\% CI 1.097 to 6.147); table 4).

\section{Immunohistochemical results of KIT-positive and KIT-negative GISTs}

Table 5 presents immunohistochemical features of KIT-positive and KIT-negative GISTs. KIT immunostaining results of two representative cases of KIT-negative GIST are shown in fig 1 $(\mathrm{B}, \mathrm{D})$. All KIT-negative GISTs were completely negative for SMA and desmin. Moreover, KIT-negative GISTs showed lower expression rates for $\mathrm{CD} 34, \mathrm{Bcl}-2$ and $\mathrm{PKC} \theta$ than KIT-positive GISTs; these differences were statistically significant.

\section{Mutational analyses of KIT-positive and KIT-negative GISTs}

Mutational analyses on 62 KIT-positive cases revealed KIT exon 9 mutations in $4.8 \%$ and KIT exon 11 mutation in $50.0 \%$ (table 6). All exon 9 mutations were in-frame insertions of six nucleotides, which resulted in the duplication of alanine 501 and tyrosine 502. The most common type of exon 11 mutation (25 cases) was an in-frame deletion, which was sometimes accompanied by a point mutation. Mutational analysis of PDGFRA was not performed for KIT-positive GISTs. For KITnegative GISTs, PDGFRA exon 18 mutations were found in six cases (30.0\%; table 6); all mutations were missense mutations leading to the substitution of valine for aspartic acid 842 (D842V). The remaining 14 KIT-negative GISTs had no detectable KIT or PDGFRA mutation, although it should be

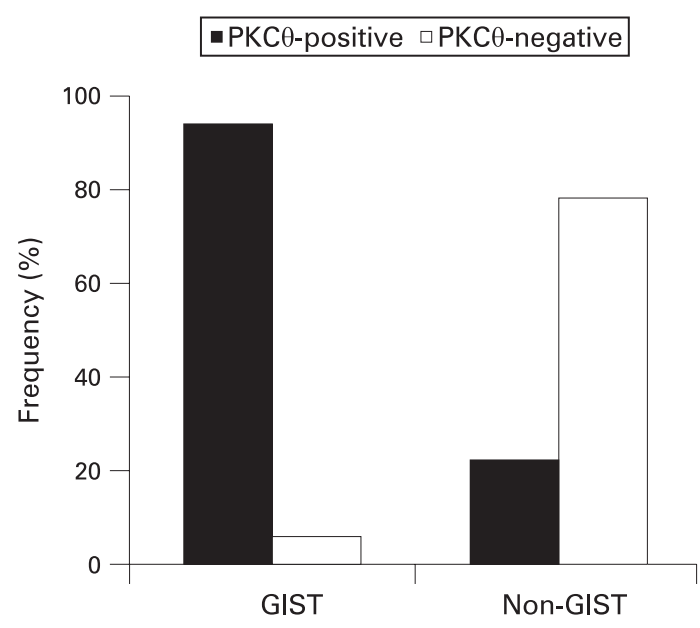

Figure 3 Frequency of protein kinase $\mathrm{C}$ theta (PKC $\theta$ ) expression in gastrointestinal stromal tumours (GISTs) and non-GISTs by immunohistochemistry. PKC $\theta$ is expressed in 231 (93.9\%) of 246 GISTs and in $14(21.9 \%)$ of 64 non-GISTs.

noted that only exons 9 and 11 of KIT and exons 12 and 18 of PDGFRA were analysed in this study.

Table 7 describes the characteristics of the six KIT-negative GISTs harbouring a PDGFRA exon 18 mutation. Five of these six occurred in the stomach and showed an epithelioid histology. Of these five patients, one died of GIST. However, precise survival analysis was not possible because of the small number of patients in this group. All six cases were positive for PKC 0 IHC. One case, a 53-year-old male patient, is illustrated in fig $1(\mathrm{~A}, \mathrm{~B})$.

\section{PKC $\theta$ expression status in GISTs and non-GISTs}

In non-neoplastic regions, we detected positive cytoplasmic staining in interstitial cells of Cajal of the gastrointestinal tract and in the nerve plexus. In GISTs, PKC $\theta$ was expressed in $93.9 \%$ of available cases but in only 15 (75\%) of 20 KIT-negative cases. PKC $\theta$ IHC showed diffuse cytoplasmic staining with weak, moderate or strong intensity in 21, 148 and 62 GISTs, respectively.

Interestingly, 14 (21.9\%) of 64 non-GISTs also had expression of PKC $\theta$ (figs 3 and 4). The PKC $\theta$-positive non-GISTs were as follows: 6/35 leiomyomas, 4/7 schwannomas, 2/7 leiomyosarcomas, and 2/13 desmoid tumours (fig 4C-F). However, the staining intensity of non-GISTs tended to be lower than that of GISTs; in PKC $\theta$ IHC of non-GIST cases, cytoplasmic staining with weak or moderate intensity was observed in 2 and 12 nonGISTs, respectively, and none showed strong staining intensity. Specifically, all four PKCO-positive schwannomas showed multifocal staining with moderate intensity.

Table 7 Characteristics of the six KIT-negative gastrointestinal stromal tumours with a platelet-derived growth factor receptor $\alpha$ (PDGFRA) mutation

\begin{tabular}{|c|c|c|c|c|c|c|c|}
\hline Age $(y) / \operatorname{sex}$ & Site & Size $(\mathrm{cm})$ & Mitoses/50 HPF & Cell type & Survival & PKC $\theta$ IHC & $\begin{array}{l}\text { PDGFRA } \\
\text { mutation }\end{array}$ \\
\hline $55 / \mathrm{M}$ & Stomach & 6.0 & 2 & $E$ & Alive & + & D842V \\
\hline $50 / F$ & Omentum & 28.0 & 25 & $E$ & Dead & + & D842V \\
\hline 48/M & Stomach & 6.0 & 8 & $E$ & Alive & + & D842V \\
\hline 49/M & Stomach & 4.5 & 2 & $S$ & Alive & + & D842V \\
\hline $62 / \mathrm{M}$ & Stomach & 1.5 & 1 & $E$ & Alive & + & D842V \\
\hline $53 / \mathrm{M}$ & Stomach & 3.0 & 1 & $E$ & Alive & + & D842V \\
\hline
\end{tabular}

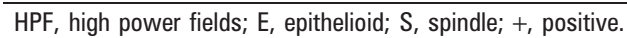


Figure 4 Representative

immunohistochemical staining of protein kinase C theta (PKC $\theta$ ). (A) PKC $\theta$-positive gastrointestinal stromal tumour (GIST). (B) PKCO-negative GIST. (C) PKCOnegative leiomyoma. (D) PKC $\theta$-positive schwannoma. (E) PKC $\theta$-positive leiomyoma. (F) PKC $\theta$-positive desmoid tumour. Original magnification, $\times 200$.
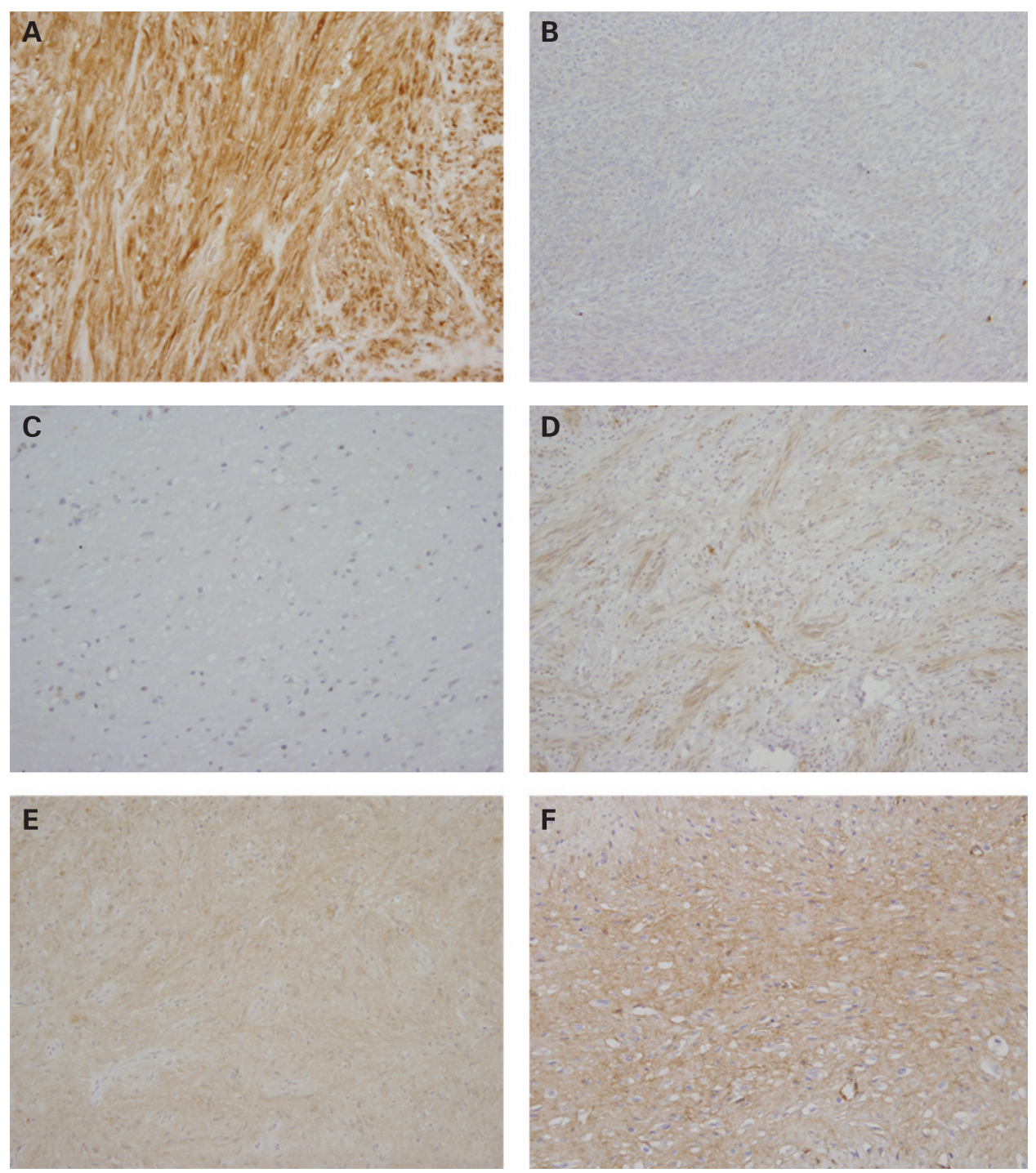

\section{DISCUSSION}

GIST is characterised by the expression of receptor tyrosine kinase KIT, ${ }^{2}$ and KIT IHC positivity has been considered as a diagnostic feature of GIST. ${ }^{2}{ }^{3}$ However, several reports have described a small subset of GISTs with little or no KIT expression. ${ }^{11}{ }^{12}$ Recently, mutations of KIT and PDGFRA were identified in a subset of KIT-negative GISTs, which strongly supports the existence of KIT-negative GISTs. However, the diagnosis of KIT-negative GISTs without KIT or PDGFRA mutation is still problematic. In our study, the diagnostic criteria used for KIT-negative GISTs were a mesenchymal tumour consistent with GIST clinically and histologically and negativity for desmin and SMA by IHC. According to these criteria, 20 cases (7.9\%) were categorised as KIT-negative GISTs; of these, 14 cases (70\%) had no detectable KIT or PDGFRA mutation according to our mutational analysis.

The mutational rate of KIT and PDGFRA in KIT-negative GISTs according to our data is lower than previously reported. ${ }^{13}{ }^{14}$ In our study, six KIT-negative GISTs harboured a mutation of PDGFRA exon 18; none showed a mutation of PDGFRA exon 12 and KIT exons 9 and 11. Medeiros et al identified a mutation of KIT exons 9 and 11 in one and three cases, respectively, and a mutation of PDGFRA exons 12, 14 and 18 in two, one and 15 cases, respectively, in a study of 25
KIT-negative GISTs; they also showed that none had a mutation of either exon 13 or 17 of KIT. ${ }^{13}$ Debiec-Rychter et al reported that three of seven KIT-negative GISTs harboured a mutation of PDGFRA exon 18 and none had any mutation of KIT exons 9, 11, 13, and 17 and PDGFRA exon 12. ${ }^{14}$ The relatively low mutational rate according to our results may be due to the small number of KIT and PDGFRA exons included in the mutational analysis, and the quality of paraffin-embedded tissues. Future mutational analyses of the entire coding region of KIT will be needed to elucidate the precise frequency of mutation and to investigate the possibility that mutations other than those of KIT and PDGFRA also underlie the pathogenesis of GIST. In addition, ploidy level analysis by fluorescence in situ hybridisation and karyotype analysis will be helpful in confirming the diagnosis of GIST for the cases with no KIT or PDGFRA mutation. ${ }^{14}$

KIT-negative GISTs are thought to differ from KIT-positive GISTs with respect to their clinicopathological, immunohistochemical and genetic features. ${ }^{13-15}$ Our large-scale study found that KIT-negative GISTs are more likely to originate in colon, omentum or peritoneum, have an epithelioid histology, and be classified as high risk. These clinicopathological findings were largely corroborated with previous reports on KIT-negative GISTs, ${ }^{13-15}$ but differ in that KIT-negative GISTs were more 
likely to locate in colon besides omentum and peritoneum. However, this finding agrees with a report of Miettinen et al, documenting that only $76 \%$ of 25 GISTs in colon were positive for KIT. ${ }^{23}$ In addition, we revealed that KIT-negative GISTs showed lower expression rates of CD34, Bcl-2, and PKC $\theta$ than KIT-positive GISTs, and 30\% of KIT-negative GISTs harboured a PDGFRA mutation. Specifically, we characterised six cases of KIT-negative GISTs with a PDGFRA mutation. All harboured the classic D842V mutation of exon 18; most originated in stomach and had epithelioid cell histology, in agreement with previous reports. ${ }^{13} 24$

Our study showed that patients with KIT-negative GISTs had a poorer OS rate than those with KIT-positive GISTs by log-rank test, and that negative KIT expression was an independent prognostic factor by multivariate Cox regression analysis for OS using the risk of aggressive behaviour and the status of imatinib treatment as covariates. These finding suggest that negative KIT protein expression may be associated with aggressiveness of tumour, although further study is required to elucidate this.

To the best of our knowledge, our report is the first to show that KIT expression status (positive vs negative) is an independent prognostic factor for OS of patients with GIST. Only a few reports stating survival differences according to KIT expression status could be found. Chirieac et al reported that there was a trend toward a superior 2-year progression-free survival in patients whose tumours demonstrated low KIT expression compared with those with strong KIT expression ( $p=0.012$, log-rank test) among 106 GIST patients who were treated with imatinib. ${ }^{25}$ The results do not agree with our results, which may be due to the difference in study population (all were treated with imatinib in their report), or the difference in cut-off value used when classifying study cases according to KIT expression status. Although the number of KIT-negative GISTs is only 20 in this study, we anticipate that our findings will help to predict the clinical course of patients and define a subgroup with unfavourable prognosis in GIST. Results will be useful for selecting patients who are expected to benefit from imatinib therapy.

A subset of KIT-negative GISTs, such as GISTs with a PDGFRA mutation, was found to be responsive to imatinib. ${ }^{16}$ These findings emphasise that GIST in KIT-negative cases should not be missed. In addition, it was recently reported that a subset of GISTs without KIT or PDGFRA mutation was also responsive to imatinib. ${ }^{16}$ This observation suggests that mechanisms other than mutations of KIT or PDGFRA play important roles in the pathogenesis of GIST.

Recently, PKC $\theta$ IHC has been raised as a diagnostic marker of GIST, especially for KIT-negative GISTs. ${ }^{15}{ }^{18-20}$ DNA microarraybased gene expression studies have revealed that the gene encoding PKC $\theta$ is overexpressed in GISTs, ${ }^{21}{ }^{22}$ and IHC showed that PKC $\theta$ protein is highly expressed in GIST tissues. ${ }^{15}{ }^{18-20} \mathrm{PKC}$ is a serine/threonine kinase that controls cell proliferation, differentiation and motility. ${ }^{26}$ Specifically, PKC $\theta$ is considered to be involved in T-cell activation, ${ }^{18}{ }^{27}$ skeletal muscle signal transduction ${ }^{18} 28$ and neuronal differentiation. ${ }^{18} 29$ Some previous reports have suggested that PKC $\theta$ is not only sensitive but also specific as a diagnostic marker for GIST. ${ }^{15}$ 18-20 PKC $\theta$ was expressed in $72-100 \%$ of GISTs on IHC in previous reports. ${ }^{15}{ }^{18-20}$ The results for non-GIST tumours were variable; 47 non-GIST tumours, ${ }^{18}$ 2/10 leiomyosarcomas and $1 / 10$ schwannomas, ${ }^{20} 3 / 21$ schwannomas and 0/4 leiomyosarcomas, ${ }^{15}$ and $4 / 10$ melanomas and $4 / 15$ schwannomas ${ }^{19}$ were positive for PKC $\theta$ IHC. The present study documented that PKC $\theta$ was

\section{Take-home messages}

- KIT-negative gastrointestinal stromal tumours (GISTs) are different from KIT-positive GISTs; KIT-negative GISTs were more likely to originate at the omentum or peritoneum, have an epithelioid histology, and be classified as high risk in this study.

- KIT-negative GISTs had a poorer overall survival rate than those with KIT-positive GISTs in Kaplan-Meier survival analysis. Negative KIT expression was an independent prognostic factor in multivariate Cox regression analysis for overall survival using the risk of aggressive behaviour and the status of imatinib treatment as covariates.

- While protein kinase $\mathrm{C}$ theta (PKC $\theta$ ) immunohistochemistry is a sensitive diagnostic marker for GIST, its usefulness is limited because of the relatively low sensitivity in KIT-negative GISTs, and positivity in some tumours other than GIST.

expressed in $93.9 \%$ of 246 GISTs and also in 6/35 leiomyomas, $4 / 7$ schwannomas and 2/7 leiomyosarcomas. The variety of the PKC $\theta$ results may be due to differences in IHC methods. Our study used autoclaving in Borg Decloaking Chamber (Biocare Medial), 1:15 of PKC $\theta$ antibody (BD Biosciences), and an avidin-biotin-peroxidase complex kit (Vectastatin Elite ABC Kit PK-6100); other studies used microwave or autoclaving, 1:50 or 1:100 of PKC $\theta$ antibody (BD Biosciences), and Dako EnVision+ System. ${ }^{18-20}$ In addition, the results of PKC $\theta$ IHC for KIT-negative GISTs were variable: $75 \%$ of the 20 cases exhibited PKC $\theta$ positivity in the present study; proportions were $72 \%$ of 18 in the study of Duensing et al, ${ }^{20}$ all six of Motegi et $a l,{ }^{15}$ and all four of Kim et al. ${ }^{19}$ The discrepancy of the results may be due to difference of selection criteria of KIT-negative GISTs besides differences of IHC methods.

According to our results of PKC $\theta$ IHC, we conclude that PKC $\theta$ is a sensitive marker, but its application as a diagnostic marker of GIST is limited because its expression was relatively low in KIT-negative GISTs and it was also expressed in some non-GISTs. Additional studies on larger populations are required to confirm these findings because of the low number of KIT-negative GISTs in the current study.

Funding: This work was supported by the 21C Frontier Functional Human Genome Project of the Korean Ministry of Science and Technology (\#FG06-11-03).

Competing interests: None declared.

\section{REFERENCES}

1. Huizinga JD, Thuneberg $L$, Kluppel $M$, et al. W/kit gene required for interstitial cells of Cajal and for intestinal pacemaker activity. Nature 1995;373:347-9.

2. Sarlomo-Rikala M, Kovatich AJ, Barusevicius A, et al. CD117: a sensitive marker for gastrointestinal stromal tumors that is more specific than CD34. Mod Pathol 1998:11:728-34.

3. Fletcher CD, Berman JJ, Corless C, et al. Diagnosis of gastrointestinal stromal tumors: a consensus approach. Hum Pathol 2002;33:459-65.

4. Hirota S, Isozaki K, Moriyama Y, et al. Gain-of-function mutations of c-kit in human gastrointestinal stromal tumors. Science 1998;279:577-80.

5. Rubin BP, Singer S, Tsao C, et al. KIT activation is a ubiquitous feature of gastrointestinal stromal tumors. Cancer Res 2001;61:8118-21.

6. Corless CL, Fletcher JA, Heinrich MC. Biology of gastrointestinal stromal tumors. J Clin Oncol 2004;22:3813-25.

7. Hirota S, Ohashi A, Nishida T, et al. Gain-of-function mutations of platelet-derived growth factor receptor alpha gene in gastrointestinal stromal tumors. Gastroenterology 2003;125:660-7.

8. Heinrich MC, Corless CL, Duensing A, et al. PDGFRA activating mutations in gastrointestinal stromal tumors. Science 2003;299:708-10.

9. Demetri GD, von Mehren M, Blanke CD, et al. Efficacy and safety of imatinib mesylate in advanced gastrointestinal stromal tumors. N Engl J Med 2002;347:472-80. 
10. van Oosterom AT, Judson I, Verweij J, et al. Safety and efficacy of imatinib (STI571) in metastatic gastrointestinal stromal tumours: a phase I study. Lancet 2001;358:1421-3.

11. Miettinen M, Sobin LH, Sarlomo-Rikala M. Immunohistochemical spectrum of GISTs at different sites and their differential diagnosis with a reference to CD117 (KIT). Mod Pathol 2000;13:1134-42.

12. Miettinen M, Lasota J. Gastrointestinal stromal tumors-definition, clinical, histological, immunohistochemical, and molecular genetic features and differential diagnosis. Virchows Arch 2001;438:1-12.

13. Medeiros F, Corless CL, Duensing A, et al. KIT-negative gastrointestinal stromal tumors: proof of concept and therapeutic implications. Am J Surg Pathol 2004;28:889-94.

14. Debiec-Rychter M, Wasag B, Stul M, et al. Gastrointestinal stromal tumours (GISTs) negative for KIT (CD117 antigen) immunoreactivity. J Pathol 2004;202:430-8.

15. Motegi A, Sakurai S, Nakayama H, et al. PKC theta, a novel immunohistochemical marker for gastrointestinal stromal tumors (GIST), especially useful for identifying KITnegative tumors. Pathol Int 2005;55:106-12.

16. Heinrich MC, Corless CL, Demetri GD, et al. Kinase mutations and imatinib response in patients with metastatic gastrointestinal stromal tumor. J Clin Oncol 2003;21:4342-9.

17. West RB, Corless CL, Chen X, et al. The novel marker, DOG1, is expressed ubiquitously in gastrointestinal stromal tumors irrespective of KIT or PDGFRA mutation status. Am J Pathol 2004;165:107-13.

18. Blay $\mathbf{P}$, Astudillo A, Buesa JM, et al. Protein kinase $\mathrm{C}$ theta is highly expressed in gastrointestinal stromal tumors but not in other mesenchymal neoplasias. Clin Cancer Res 2004;10:4089-95.

19. Kim KM, Kang DW, Moon WS, et al. PKCtheta expression in gastrointestinal stromal tumor. Mod Pathol 2006;19:1480-6.
20. Duensing A, Joseph NE, Medeiros F, et al. Protein kinase C theta (PKCtheta) expression and constitutive activation in gastrointestinal stromal tumors (GISTs). Cancer Res 2004;64:5127-31.

21. Allander SV, Nupponen NN, Ringner M, et al. Gastrointestinal stromal tumors with KIT mutations exhibit a remarkably homogeneous gene expression profile. Cancer Res 2001:61:8624-8.

22. Nielsen TO, West RB, Linn SC, et al. Molecular characterisation of soft tissue tumours: a gene expression study. Lancet 2002;359:1301-7.

23. Miettinen M, Sarlomo-Rikala M, Sobin LH, et al. Gastrointestinal stromal tumors and leiomyosarcomas in the colon: a clinicopathologic, immunohistochemical, and molecular genetic study of 44 cases. Am J Surg Pathol 2000;24:1339-52.

24. Wardelmann E, Hrychyk A, Merkelbach-Bruse $S$, et al. Association of plateletderived growth factor receptor alpha mutations with gastric primary site and epithelioid or mixed cell morphology in gastrointestinal stromal tumors. J Mol Diagn 2004;6:197-204.

25. Chirieac LR, Trent JC, Steinert DM, et al. Correlation of immunophenotype with progression-free survival in patients with gastrointestinal stromal tumors treated with imatinib mesylate. Cancer 2006;107:2237-44.

26. Nishizuka Y. Intracellular signaling by hydrolysis of phospholipids and activation of protein kinase C. Science 1992;258:607-14.

27. Altman A, Villalba M. Protein kinase C-theta (PKCtheta): it's all about location, location, location. Immunol Rev 2003;192:53-63.

28. Hilgenberg $\mathbf{L}$, Miles $\mathrm{K}$. Developmental regulation of a protein kinase $\mathrm{C}$ isoform localized in the neuromuscular junction. J Cell Sci 1995;108:51-61.

29. Sparatore B, Patrone M, Passalacqua M, et al. Neuronal differentiation of PC12 cells involves changes in protein kinase $\mathrm{C}$-theta distribution and molecular properties. Biochem Biophys Res Commun 2000;275:149-53.

\section{Invitation to submit images for consideration as a Cover}

Readers are invited to submit images for consideration as a Cover. Cover images are not necessarily linked to a specific paper in that issue but rather are selected for their scientific/clinical interest and aesthetic appeal. We ask that readers only submit those images for which they hold the copyright. Colour images are preferred, should be a minimum of 600 dpi and in CMYK mode. Please submit your images to jclinpath@bmjgroup.com in the first instance. Please also include a clear and concise legend explaining the image. All images will be credited to the appropriate supplier. 